\title{
Global ocean warming tied to anthropogenic forcing
}

\author{
Bernhard K. Reichert, ${ }^{1}$ Reiner Schnur, and Lennart Bengtsson \\ Max Planck Institute for Meteorology, Hamburg, Germany
}

Received 22 August 2001; accepted 28 December 2001; published 12 June 2002.

[1] Observed global ocean heat content anomalies over the past five decades agree well with an anthropogenically forced simulation using the European Center/Hamburg coupled general circulation model (GCM) ECHAM4/OPYC3 considering increasing greenhouse gas concentrations, the direct and indirect effect of sulphate aerosols, and anthropogenic changes in tropospheric ozone. An optimal detection and attribution analysis confirms that the simulated climate change signal can be detected in the observations in both the upper $300 \mathrm{~m}$ and $3000 \mathrm{~m}$ of the water column and that the observed changes in ocean heat content are consistent with those expected from the anthropogenically forced GCM integration. This suggests that anthropogenic forcing is a likely explanation for the observed global ocean warming over the past five decades. INDEX TERMS: 1635 Global Change: Oceans (4203); 1620 Global Change: Climate dynamics (3309); 4532 Oceanography: Physical: General circulation

\section{Introduction}

[2] Due to its large heat capacity and mass, the world ocean is able to store or release large amounts of heat over long periods of time through interaction with the atmosphere. Global ocean temperature changes are a consequence of net surface heating imbalances. It has previously been found [Bengtsson, 1996] that a transient integration with the coupled general circulation model (GCM) ECHAM4/OPYC3 [Roeckner et al., 1999] forced by increasing greenhouse gas concentrations since 1860 (integration GHG) resulted in a long-term positive total surface heat flux into the world ocean leading to a heat content increase of about $5 \times 10^{23} \mathrm{~J}$ within the time period $1860-1990$. Validation of this quantity via observations has been difficult since reliable data for the past, especially for the deep oceans are sparse. Such a validation is however strongly desirable since it may permit the detection of possible anthropogenic signals in the climatically-critical deep ocean, thus significantly extending results from climate change detection studies based on nearsurface temperature alone [e.g. Hasselmann, 1997; Hegerl et al., 1997; Barnett et al., 1999; Allen et al., 2001]. Recently published observational data [Levitus et al., 2000] now allow validation at least for the time period of the past five decades. The data show a positive trend of the upper world ocean's heat content, with significant differences in the warming rate for individual ocean basins. In this study, we will compare these data with an anthropogenically forced coupled GCM integration leading to important conclusions on the detection and attribution of climate change. Parallel to this study, encouraging results have recently been obtained using the Parallel Climate Model (PCM) [Barnett et al., 2001] and the GFDL model [Levitus et al., 2001]. We provide a new perspective using the fourth generation of the European Center/Hamburg GCM (ECHAM4)

\footnotetext{
${ }^{1}$ Now at Lamont-Doherty Earth Observatory, Columbia University, Palisades, New York.
}

Copyright 2002 by the American Geophysical Union. 0094-8276/02/2001GL013954 coupled to an isopycnal ocean model (OPYC3). We will furthermore explicitly investigate uncertainties related to observational sampling.

\section{GCM Experiments}

[3] The ECHAM4 model [Roeckner et al., 1996] has 19 vertical levels and is integrated at T42 horizontal resolution corresponding to a latitude-longitude grid of about $2.8^{\circ} \times 2.8^{\circ}$. The model is coupled to the full ocean general circulation model OPYC3 [Oberhuber, 1993] consisting of three sub-models: interior ocean, surface mixed-layer, and sea ice (dynamic-thermodynamic sea ice model including viscous plastic rheology). OPYC3 has 11 layers; the horizontal resolution poleward of $36^{\circ}$ latitude is identical to that of ECHAM4 (T42) while, at lower latitudes, it is gradually increased to $0.5^{\circ}$ at the equator. Experiments with the coupled model version ECHAM4/OPYC3 discussed in this study are described in detail in Roeckner et al. [1999]. In the 300-year control integration, the concentrations of carbon dioxide, methane, and nitrous oxide are fixed at the observed 1990 values [IPCC, 1990]. The transient integration GSDIO is integrated for the period 1860-2050 and considers observed (1860-1990) and estimated future (1990-2050) increases [IPCC, 1996; scenario IS92a] of greenhouse gas concentrations for $\mathrm{CO}_{2}, \mathrm{CH}_{4}, \mathrm{~N}_{2} \mathrm{O}$, and several industrial gases. It also includes the direct radiative effect of sulphate aerosols, the indirect effect of aerosols on cloud albedo, and the radiative forcing due to anthropogenic changes in tropospheric ozone. The model uses annual mean flux adjustments on heat and freshwater. The model-specific drift in the control integration is approximated by a cubic function and is consistently removed from all integrations. In addition to the 300years ECHAM4/OPYC3 control integration, natural variability of ocean heat content is further estimated using a 1000-year control integration of ECHAM4 coupled to the HOPE ocean model [Wolff et al., 1997; Legutke and Voss, 1999]. All heat content anomalies are reported as anomalies relative to the mean over the entire time period of interest.

\section{Impact of Spatio-Temporal Data Coverage}

[4] Observed and simulated transient heat content anomalies (GSDIO integration) in the upper $300 \mathrm{~m}$ and $3000 \mathrm{~m}$ of individual ocean basins are shown in Figures 1 and 2 respectively. The corresponding linear trends along with the percentage of variance accounted for by the trends are presented in Table 1. Two different spatial sampling methods are applied to the simulated anomalies. For the first method (solid lines in Figures 1 and 2; middle column in Table 1), the simulated anomalies are masked using the observational data distribution. This means that, after interpolating model output to the three-dimensional observational grid, simulated heat content anomalies are calculated exclusively from grid volumes which correspond to non-missing observations as described in the "gp" observational data set [Antonov et al., 1998]. It needs to be stressed however that there are grid volumes in the "gp" set that are declared as "observed" but are actually filled in by a spatial interpolation scheme using measurements in the neighbourhood of the volumes. This may have some influence on the calculated heat contents in specific 


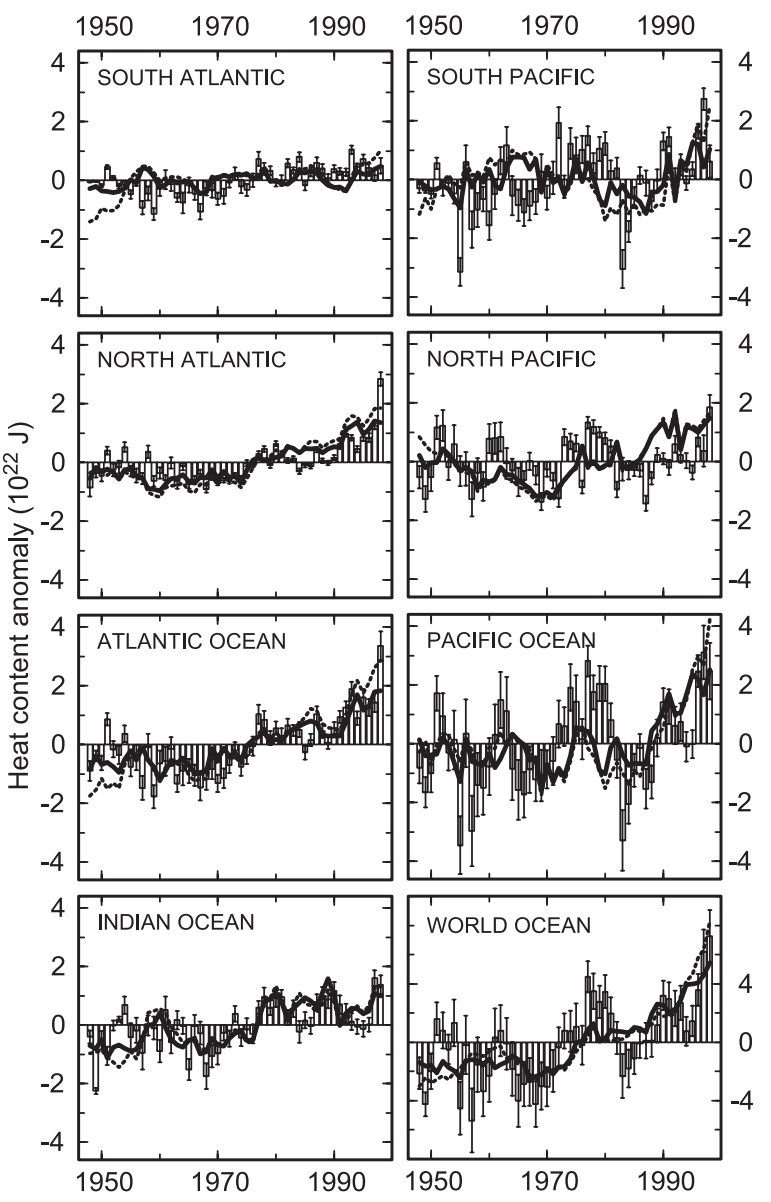

Figure 1. Observed and simulated annual ocean heat content anomalies (unit: $10^{22} \mathrm{~J}$ ) in the upper $300 \mathrm{~m}$ of the water column for individual ocean basins within the period 1948-1998. Bars show observational data including \pm 1 standard error [Levitus, 2000]. Solid lines represent simulated heat content anomalies calculated from the ECHAM4/OPYC3 coupled GCM integration GSDIO masked using the observational data distribution. Dotted lines represent simulated heat content anomalies calculated for full model ocean basins.

regions especially of the deep ocean, we suspect however only a minor impact with respect to the calculated basin-wide averages. For comparison with the masked simulation, the second sampling method (dotted lines in Figures 1 and 2; right column in Table 1) consists of simulated heat content anomalies calculated for the full model ocean basins, regardless of the existence of observational data at each grid volume.

[5] In the upper $300 \mathrm{~m}$, differences due to the sampling method are generally small (Table 1). The overall trend for the world ocean calculated from the full ocean basins is about $10 \%$ higher compared to the restricted basin. Such an increase could be expected simply when assuming a uniform trend in the larger water volume considered. In the upper $3000 \mathrm{~m}$, heat content anomalies are sensitive to the lower observational data coverage for the South Pacific in the 1970's and 1980's indicating that this region particularly suffers from a lack of observations (Figure 2). In spite of differences for individual basins, the impact of the sampling method on the entire world ocean's heat content trend is however small $\left(43.0 \times 10^{20} \mathrm{~J} / \mathrm{a}\right.$ versus $\left.45.1 \times 10^{20} \mathrm{~J} / \mathrm{a}\right)$. For the period before 1955, missing data have a noticeable impact, trends are however not affected since they are obtained for the time period after 1955 only [Levitus et al., 2000].

\section{Simulated and Observed Ocean Warming Trends}

[6] Since the coupled GCM integration produces its own natural internal climate variability superimposed on the general trends, one can naturally not expect a perfect match between amplitude and phasing of variations in observed and simulated heat content anomalies, especially when looking at individual ocean basins and below decadal time scales. We therefore focus on linear trends over the observational time period (Table 1) and on decadal averages in the next section.

[7] The simulated global ocean heat content trends masked using the observational data distribution agree well with observations (Table 1), differences are found to be below $10 \%$ for both the upper $300 \mathrm{~m}$ and $3000 \mathrm{~m}$. In the upper $300 \mathrm{~m}$, we also find a good agreement for the individual ocean basins (Figure 1). In the upper $3000 \mathrm{~m}$, trends for the Atlantic Ocean agree well, simulated trends are however too strong in the Indian and too weak in the Pacific Ocean (Figure 2). Some of the differences may be due to the changing data coverage and/or quality of data for individual time periods, as discussed above. Another source of disagreement are model deficiencies or forcing mechanisms not considered in the model integration, e.g. the absence of volcanic forcing. However, we think that the main differences may be due to the impact of internal climate variability: We note that there is a greater resemblance between the simulated and observed trends on the global scale than on the basin scale. This implies that the discrepancies for

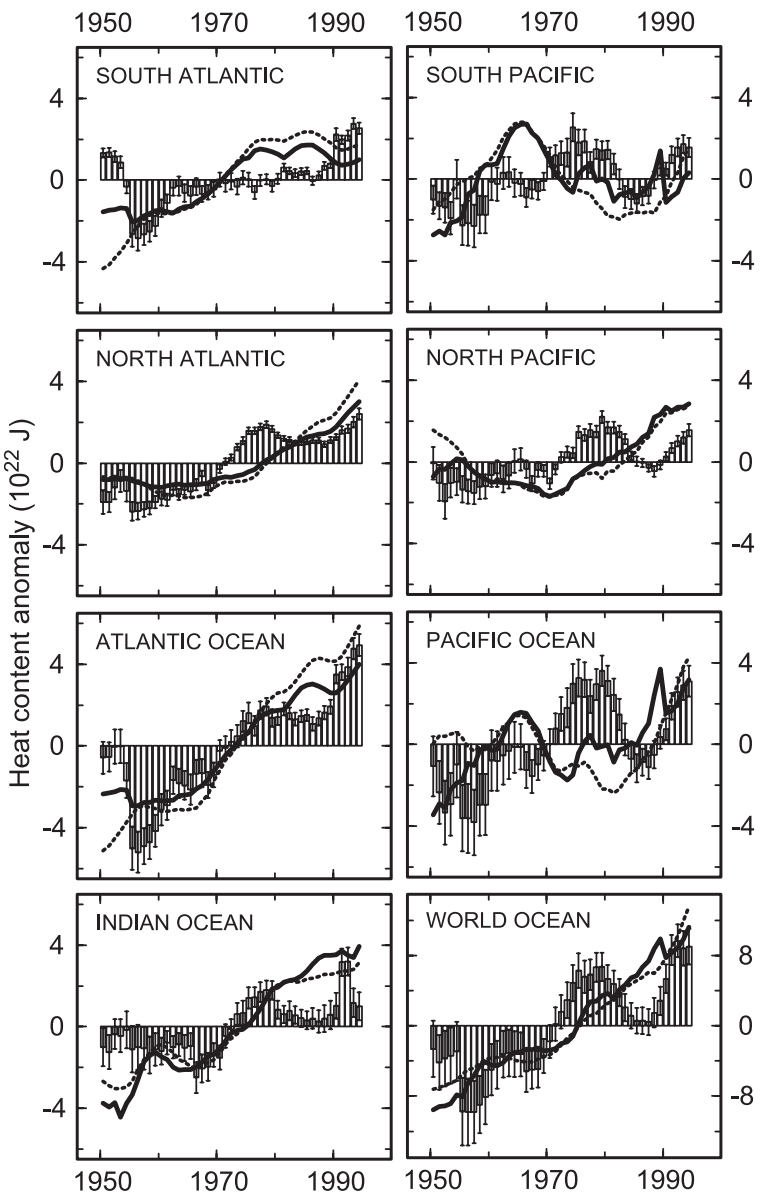

Figure 2. Observed and simulated 5-year running means of ocean heat content anomalies (unit: $10^{22} \mathrm{~J}$ ) in the upper $3000 \mathrm{~m}$ of the water column within the period 1950-1995. Bars and lines as in Figure 1. 
Table 1. Calculated Linear Heat Trends (unit $10^{20} \mathrm{~J} / \mathrm{a}$ ) in the Upper $300 \mathrm{~m}$ of Individual Ocean Basins for the Period 19481998 and in the Upper $3000 \mathrm{~m}$ for the Period 1955-1995

\begin{tabular}{lcrrr}
\hline Ocean & Depth & Observations & $\begin{array}{r}\text { Masked } \\
\text { Simulation }\end{array}$ & $\begin{array}{r}\text { Full Basin } \\
\text { Simulation }\end{array}$ \\
\hline Atlantic & $0-300 \mathrm{~m}$ & $4.7(48 \%)$ & $4.5(75 \%)$ & $6.8(81 \%)$ \\
Indian & $0-300 \mathrm{~m}$ & $3.0(33 \%)$ & $3.8(61 \%)$ & $4.0(58 \%)$ \\
Pacific & $0-300 \mathrm{~m}$ & $3.8(13 \%)$ & $3.8(34 \%)$ & $3.4(18 \%)$ \\
World & $0-300 \mathrm{~m}$ & $11.3(37 \%)$ & $12.3(76 \%)$ & $13.8(70 \%)$ \\
Atlantic & $0-3000 \mathrm{~m}$ & $21.9(91 \%)$ & $19.8(96 \%)$ & $26.5(95 \%)$ \\
Indian & $0-3000 \mathrm{~m}$ & $8.8(57 \%)$ & $18.8(94 \%)$ & $15.3(88 \%)$ \\
Pacific & $0-3000 \mathrm{~m}$ & $11.2(38 \%)$ & $6.0(28 \%)$ & $2.0(2 \%)$ \\
World & $0-3000 \mathrm{~m}$ & $41.9(73 \%)$ & $45.1(96 \%)$ & $43.0(91 \%)$ \\
\hline
\end{tabular}

Percentages of variance accounted for by the trends are shown in brackets. Trends are shown for observations, GCM simulations masked using the observational data distribution ("Masked Simulation"), and GCM simulations for full model ocean basins ("Full Basin Simulation").

individual basins may be a reflection of basin-scale internal variability, and there is no reason to expect that a single model realization would entirely duplicate this variability. Note also that the low variances accounted for by the linear trends for some ocean basins (e.g. less than $40 \%$ for the Pacific in the upper $3000 \mathrm{~m}$, Table 1) make the comparison between simulated and observed trends for individual basins more difficult.

\section{Detection and Attribution}

[8] Simulated trends in global ocean heat content using the scenario experiment GSDIO over the recent five decades are large in comparison with the two multi-century control integrations (Figure 3). The results obtained so far represent elements of a simple detection and attribution (D\&A) analysis: trends are large in comparison with the control variability (detection), and agreement between the forced GCM simulation and observations is good (attribution; Figures 1 and 2). These findings are substantiated by a formal optimal D\&A analysis [Hegerl et al., 1997; Tett et al., 1999; Barnett et al., 1999; Allen et al., 2001; IPCC, 2001]. The diagnostic used consists of the time-space pattern concatenated from the decadal averages of ocean heat contents during the last

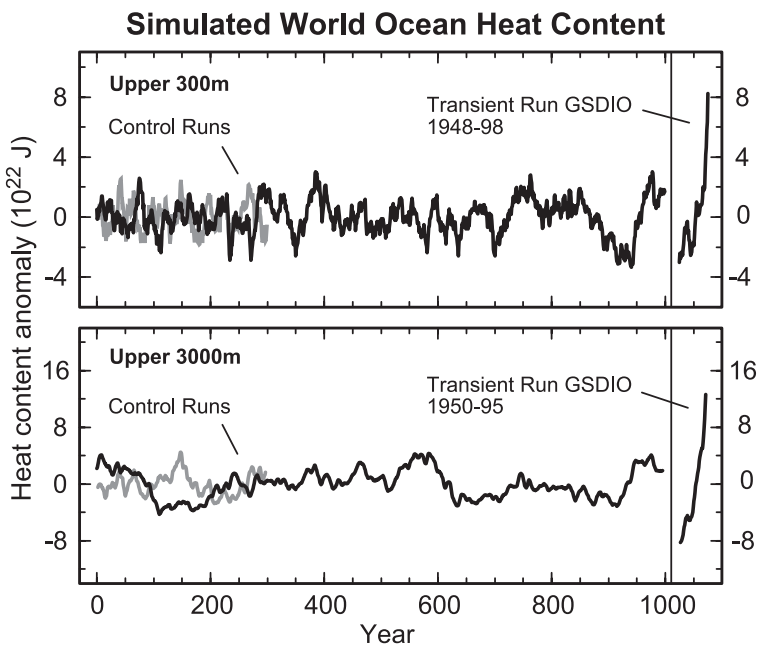

Figure 3. Simulated world ocean heat content anomalies (unit: $10^{22} \mathrm{~J}$ ) for the transient integration GSDIO (solid lines, right part of diagrams) over the recent five decades are large in comparison with the control integrations of ECHAM4/OPYC3 (300 years; gray line) and ECHAM4/HOPE (1000 years; solid line) in the upper $300 \mathrm{~m}$ (upper diagram) and $3000 \mathrm{~m}$ (lower diagram) of the water column.

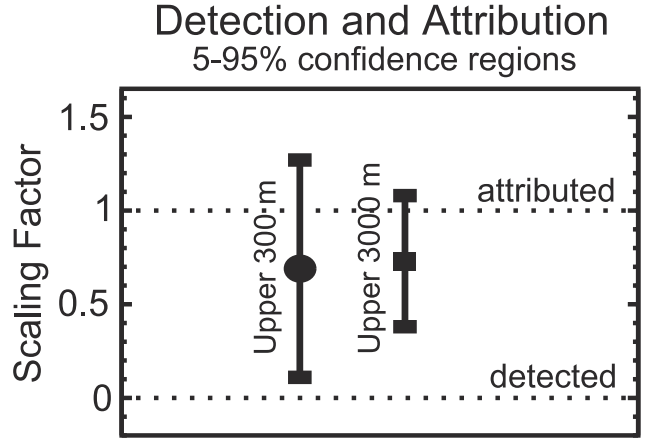

Figure 4. Optimal detection and attribution for the ECHAM4/ OPYC3 climate change scenario GSDIO and for the space-time evolution of decadal mean basin-averaged ocean heat contents during the past five decades. Symbols denote the best-fit regression coefficients ("scaling factors") for the respective fingerprint and the observations. The bars represent $5-95 \%$ confidence intervals for the scaling factors derived from the ECHAM4/HOPE control run. The lower end of the confidence intervals is above the zero line which means that the simulated climate change pattern has been "detected" in the observations at the given confidence level, i.e. the contribution of this fingerprint in the observations is larger than could be expected by chance. The confidence intervals include a scaling factor of one which means that the observed change can be "attributed" to the anthropogenic forcing in the GCM experiment, i.e. the data do not contain evidence against the hypothesis that this specific forcing caused the observed change. The ECHAM4/OPYC3 control run is used for optimal data weighing.

50 years of the observational period for the six individual ocean basins North and South Pacific, North and South Atlantic, and North and South Indian Ocean. An expected pattern of climate change due to anthropogenic forcings ("fingerprint") is obtained by computing this diagnostic from the GCM scenario experiment. The strength of this pattern in the observations ("signal") is the projection of the observed diagnostic onto the fingerprint. To evaluate whether this strength is larger than would be expected in the absence of any anthropogenic forcing, a time series of similar projections is obtained from 50-year windows of a control experiment which can then be used to derive significance levels. The optimal D\&A approach used here maximizes the signal-to-noise ratio by first normalizing all data by the noise covariance of natural variability derived from independent "control" data, thereby attenuating the influence from areas with large climate noise.

[9] Results of this procedure (Figure 4) are presented in terms of multiple regression coefficients ("scaling factors"), including their confidence intervals. They specify by what amount the model diagnostic has to be multiplied to be in best agreement with the observed diagnostic [see e.g. Chapter 12 in IPCC, 2001]. Results for both the upper $300 \mathrm{~m}$ and $3000 \mathrm{~m}$ show that the simulated ocean heat content signal from the GSDIO experiment can be detected in the observations and, in addition, that the observed change is consistent with the forcing combination used in GSDIO.

\section{Discussion and Conclusions}

[10] The coupled ECHAM4/OPYC3 integration GSDIO shows a global ocean net warming of about $23 \times 10^{22} \mathrm{~J}$ in the upper 3000 $\mathrm{m}$ over the period 1955-1995. This agrees well with the observed heat storage of about $20 \times 10^{22} \mathrm{~J}$ [Levitus et al., 2000]. Barnett et al. [2001] found a global ocean heat storage of $12 \times 10^{22} \mathrm{~J}$ using the Parallel Climate Model (PCM). Levitus et al. [2001] obtained $33 \times 10^{22} \mathrm{~J}$ using the GFDL model (which was reduced to $20 \times$ $10^{22} \mathrm{~J}$ in a separate experiment including solar and volcanic 
forcing). While the net climate forcings for the three model integrations are comparable (about $1.8 \mathrm{Wm}^{-2}$ for the ECHAM4/ OPYC and $2 \mathrm{Wm}^{-2}$ for the PCM and GFDL models for the period $1870-2000$ ), we suspect that main differences in the simulated heat contents are due to the different model sensitivities. We may obtain a rough idea of the sensitivities from CMIP2 experiments [IPCC, 2001; their Table 9.1] which show an effective climate sensitivity of $2.6^{\circ} \mathrm{C}$ for the ECHAM4/OPYC model, $1.7^{\circ} \mathrm{C}$ for the $\mathrm{PCM}$, and $4.2^{\circ} \mathrm{C}$ for the GFDL (r15 version; $\mathrm{r} 30$ not available) models for $\mathrm{CO}_{2}$ doubling. This means that the sensitivities are in line with and can at least partly explain the differences in the simulated net ocean warming values.

[11] An optimal detection and attribution analysis for the upper $300 \mathrm{~m}$ and $3000 \mathrm{~m}$ confirms that the observed changes in ocean heat content within the past five decades are consistent with those expected from the anthropogenically forced ECHAM4/OPYC GCM integration GSDIO considering increasing greenhouse gas concentrations, the direct and indirect effect of sulphate aerosols, and anthropogenic changes in tropospheric ozone. This does not mean that other climatic forcing factors (e.g. volcanic activity or solar irradiation changes that are not included in our model integration) may not partly contribute to explain observations. However, our results show that the observed increase in world ocean heat content over the past five decades is very unlikely to be a result of natural internal climate variability alone and suggest anthropogenic forcing as a possible explanation. This is in agreement with the studies by Barnett et al. [2001] and Levitus et al. [2001] showing that in spite of different model sensitivities, all three climate models are suitable in order to detect and attribute climate change in the deep oceans.

[12] We have shown that the impact of the observational data coverage on the simulated global ocean heat content trends is small (indicated also by Barnett et al. [2001]) and not relevant for the main conclusions of this study. We find a very good agreement between observed and simulated warming trends for individual ocean basins in the upper $300 \mathrm{~m}$ of the water column. Differences for individual basins in the upper $3000 \mathrm{~m}$ are supposedly mainly due to internal climate variations superimposed on the general trends. However, the simulated variations do not always add up to fully match observed global ocean heat content fluctuations. It remains, for example, difficult to explain the observed period of global ocean cooling in the upper $3000 \mathrm{~m}$ in the early 1980s (Figure 2). This cooling does not appear to be due to climate forcings since neither volcanic forcing nor solar irradiation changes are likely to have this dominant effect within this time period (J. Hansen et al., Climate forcings in GISS SI2000 simulations, submitted to JGR, 2001). Besides an investigation of observational inconsistencies, a further study using an ensemble of coupled ECHAM GCM integrations is required in order to quantify the impact of internal variations in more detail.

[13] It has been demonstrated in previous studies [e.g. Roeckner et al., 1999] that the ECHAM4/OPYC3 model is able to reproduce observed global mean surface air temperature changes over the period 1860 to present. In this study, we have been able to validate the model independently with respect to another component of the climate system: we have shown that it can reproduce the observed warming trend in the world ocean over the past five decades. These results may strengthen the confidence in the performance of the model and consequently the credibility of model-predicted surface air temperature changes for future scenarios.

[14] Acknowledgments. The authors would like to thank M. Esch, M. N. Evans, and K. Lohmann for their valuable scientific support. We thank S.
Levitus et al. for making ocean heat content data used in this study available. The study was supported by NOAA/ESH grant NA86GP0437 and by the European Commission under contracts ENV4-CT95-0072 (B. K. Reichert) and ENV4-CT97-0501 (R. Schnur). The Alexander von Humboldt Foundation is thanked for supporting B. K. Reichert as a Feodor Lynen Fellow.

\section{References}

Allen, M. R., N. P. Gillett, J. A. Kettleborough, G. Hegerl, R. Schnur, P. A. Stott, G. Boer, C. Covey, T. L. Delworth, G. S. Jones, J. F. B. Mitchell, and T. P. Barnett, Quantifying anthropogenic influence on recent nearsurface temperature change, submitted to, Rev. Geophys, 2001.

Antonov, J., S. Levitus, T. P. Boyer, M. Conkright, T. O' Brien, and C. Stephens, World Ocean Atlas 1998, Vol. 1-3, NOAA Atlas NESDIS 27-29, U.S. Gov. Printing Office, Washington D.C., 166 pp., 1998. [yearly and pentadal anomalies available from http://www.nodc.noaa. gov/OC5/]

Barnett, T. P., K. Hasselmann, M. Chelliah, T. Delworth, G. Hegerl, P. Jones, E. Rasmusson, E. Roeckner, C. Ropelewski, B. Santer, and S. Tett, Detection and attribution of recent climate change: A status report, Bull. Am. Meteorol. Soc., 80, 2631-2659, 1999.

Barnett, T. P., D. W. Pierce, and R. Schnur, Detection of anthropogenic climate change in the world's oceans, Science, 292, 270-274, 2001.

Bengtsson, L., The climate response to the changing greenhouse gas concentration in the atmosphere, in Decadal climate variability; dynamics and predictability, edited by D. L. T. Anderson and J. Willebrand, NATO ASI series, vol. 44, Springer, Berlin, 1996.

Hasselmann, K., Multi-pattern fingerprint method for detection and attribution of climate change, Clim. Dyn., 13, 601-611, 1997.

Hegerl, G., K. Hasselmann, U. Cubasch, J. F. B. Mitchell, E. Roeckner, R. Voss, and J. Waszkewitz, On multi-fingerprint detection and attribution of greenhouse gas and aerosol forced climate change, Clim. Dyn., 13, 613-634, 1997.

IPCC, Scientific Assessment of Climate Change, edited by J. T. Houghton, Jenkins, and J. J. Ephraums, Cambridge Univ. Press, New York, 365 pp., 1990.

IPCC, Climate Change 1995: The Science of Climate Change, edited by J. T. Houghton, L. G. Meira Filho, B. A. Callendar, N. Harris, A. Kattenberg, and K. Maskell, Cambridge Univ. Press, New York, 572 pp., 1996.

IPCC, Climate Change 2001: The Scientific Basis, edited by J. T. Houghton, Y. Ding, D. J. Griggs, M. Moguer, P. J. van der Linden, and D. Xiaosu, Cambridge Univ. Press, UK, 944 pp., 2001.

Legutke, S., and R. Voss, The Hamburg atmosphere-ocean coupled circulation model ECHO-G, DKRZ technical report No. 18, Deutsches Klimarechenzentrum, Hamburg, Germany, 1999.

Levitus, S., J. I. Antonov, T. P. Boyer, and C. Stephens, Warming of the world ocean, Science, 287, 2225-2229, 2000.

Levitus, S., J. I. Antonov, J. Wang, T. L. Delworth, K. W. Dixon, and A. J. Broccoli, Anthropogenic warming of Earth's climate system, Science, 292, 267-270, 2001.

Oberhuber, J. M., Simulation of the Atlantic circulation with a coupled sea ice-mixed layer-isopycnal general circulation model. Part I: Model description, J. Phys. Oceanogr., 22, 808-829, 1993.

Roeckner, E., K. Arpe, L. Bengtsson, M. Christoph, M. Claussen, L. Dümenil, M. Esch, M. Giorgetta, U. Schlese, and U. Schulzweida, The atmospheric general circulation model ECHAM-4: Model description and simulation of present-day climate, Rep. 218, Max-Planck-Inst. für Meteorol., Hamburg, Germany, 1996.

Roeckner, E., L. Bengtsson, J. Feichter, J. Lelieveld, and H. Rodhe, Transient climate change simulations with a coupled atmosphere-ocean GCM including the tropospheric sulfur cycle, J. Climate, 12, 3004-3032, 1999.

Tett, S. F. B., P. A. Stott, M. R. Allen, W. J. Ingram, and J. F. B. Mitchell, Causes of twentieth century temperature change near the Earth's surface, Nature, 399, 569-572, 1999.

Wolff, J. O., E. Maier-Reimer, and S. Legutke, The Hamburg ocean primitive equation model HOPE, DKRZ technical report No. 13, Deutsches Klimarechenzentrum, Hamburg, Germany, 1997.

B. K. Reichert, R. Schnur, and L. Bengtsson, Max Planck Institute for Meteorology, Hamburg, Germany. (reichert@ldeo.columbia.edu) 